\title{
Natural gas adsorption on biomass derived activated carbons: A mini review
}

\author{
Usman D. Hamza ${ }^{1}$, Noor S. Nasri ${ }^{2}$, Jibril Mohammed ${ }^{3}$ and Zulkifil Abd. Majid ${ }^{2}$ \\ ${ }^{1,3}$ Department of Chemical Engineering, Abubakar Tafawa Balewa University Bauchi, P.M.B. 0248, Bauchi Nigeria \\ ${ }^{2}$ UTM-MPRC Institute for Oil and Gas, Resources Sustainability, Universiti Teknologi Malaysia, 81310 UTM Johor Bahru, Johor, Malaysia
}

\begin{abstract}
Activated carbon materials are good candidates for natural gas storage due excellent textural properties that are easy to enhance and modify. Natural gas is much cleaner fuel than coal and other petroleum derivatives. Storage of natural gas on porous sorbents at lower pressure is safer and cheaper compared to compressed and liquefied natural gas. This article reviews some works conducted on natural gas storage on biomass based activated carbon materials. Methane storage capacities and deliveries of the various sorbents were given. The effect of factors such as surface area, pore characteristic, heat of adsorption, packing density on the natural gas storage capacity on the activated carbons are discussed. Challenges, improvements and future directions of natural gas storage on porous carbonaceous materials are highlighted.
\end{abstract}

\section{Introduction}

Natural gas is cheap, clean [1], safe and abundant energy source [2]. Due to these advantages, its storage, transportation and utilization have attracted global attention [3]. Natural gas (NG) is composed mainly of 85-95 mol\% methane $\left(\mathrm{CH}_{4}\right)$, the remainder being carbon dioxide $\left(\mathrm{CO}_{2}\right)$, nitrogen $\left(\mathrm{N}_{2}\right)$ and small amounts of higher heavy gaseous hydrocarbons [1]. Natural gas from crude wells is known as associated gas, while those from gas wells or condensate is referred to as non-associated gas. NG from pores of coal is known as coalbed gas [2]. Until recently, Natural gas is stored as compressed natural gas $(\mathrm{CNG})$ or liquefied natural gas (LNG). In (CNG), natural gas is stored as a compressed supercritical fluid at room temperature and at maximum pressure of about 200-250 bar [1]. Therefore, $\mathrm{CNG}$ requires expensive vessels and multi-stage compression [4]. Not only that, in terms of equal fuel-tank volume, the energy density of natural gas at pressure of $20 \mathrm{MPa}$, is only $29 \%$ that of gasoline [3]. $\mathrm{NG}$ is transported overseas as liquefied natural gas (LNG) in ships, LNG requires expensive cryogenic process [4]. It is usually stored as a boiling liquid at about $\left(161^{\circ} \mathrm{C}\right)$ in a cryogenic tank at a pressure of about 14.7 psia. LNG has volumetric energy density for about $72 \%$ of that of gasoline [5].

Due to high costs, safety and operational restrictions of CNG and LNG researchers are finding alternatives [1]. ANG (Adsorbed natural gas) is viewed as alternative technology to CNG and LNG. In ANG, the gas is stored on porous material packed into a vessel at much lower pressure [3]. In ANG the storage pressure is usually in the range of $35-40$ bar. Therefore, there is improved safety and low compression costs in ANG [1].

Among solid adsorbents, activated carbons have been used and evaluated for methane adsorption. They are good candidates for natural gas storage due to large surface area, large pore volume and low density. Activated carbons with diversified microporous structures constitute an important category of potential adsorbents for natural gas storage [6]. Properties of activated carbon required for natural gas adsorption include: high adsorption capacity, high packing density, high adsorption desorption rate, ratio of amount desorbed at $0.1 \mathrm{Mpa}$ and the amount adsorbed at $4 \mathrm{Mpa}$ should be close to one [7], less susceptible to temperature changes during adsorption and desorption, extremely hydrophobic and it should be inexpensive for the final user. [10]

For ANG to be commercially viable, the ANG technology requires a methane storage target of $180 \mathrm{v} / \mathrm{v}$ at an ambient temperature, with the energy density of ANG comparable to that of current CNG technology [9]. Recently, the United States Department of Energy (DOE) reviewed the volumetric objective for adsorbed natural gas from the old value of $180 \mathrm{~cm} 3$ (STP: $273.15 \mathrm{~K}, 1$ $\mathrm{atm}) / \mathrm{cm}^{3}$ to a much ambitious value of $263 \mathrm{~cm}^{3}$ (STP: $273.15 \mathrm{~K}, 1 \mathrm{~atm}) / \mathrm{cm}^{3}$ [10]. This paper reviewed the existing literature on natural gas/methane adsorption on biomass based porous carbons. Both single and gas mixture adsorption is discussed, challenges of ANG technology and improvements in the system are given.
2. Important
ANG
Adsorbent 
For activated carbon to be considered as a good ANG material, certain parameters/properties such as adsorption capacity, deliverable gas, heat of adsorption, surface area, porosity and packing density needs to be assessed.

\subsection{Deliverable Gas and Adsorption Capacity}

Deliverable gas is the volume of gas delivered per volume of the storage container. It denotes the amount of gas released when pressure is reduced from high pressure mostly around 34 bars to atmospheric pressure. The storage capacity is usually greater than the delivered gas by about $15-30 \%$ [11]. The US Department of Energy (DOE) set target of absolute methane-adsorption capacity of $180 \mathrm{v} / \mathrm{v}$ (standard temperature and pressure equivalent volume of methane per volume of the adsorbent material) at 35 bars, under ambient temperature. $\mathrm{CH}_{4}$ storage target was reviewed in 2012 to $230 \mathrm{v} / \mathrm{v}$ [12]. Methane adsorption on olive stones grain activated carbon chemically activated by $\mathrm{ZnCl}_{2}$ led followed by physical activation with $\mathrm{CO}_{2}$ gives $110 \mathrm{~V} / \mathrm{V}$ at $298 \mathrm{~K}$ under $3.4 \mathrm{MPa}$. Most of the studies conducted reported volumetric $\mathrm{CH}_{4}$ capacities for activated carbons in the range of 100-170 $\mathrm{v} / \mathrm{v}$; therefore there is still need for improvement [12].

\subsection{Heat of Adsorption}

Adsorption of natural gas during charging into an adsorbent filled container is exothermic, while desorption is endothermic [13]. Increase in temperature brings about decrease in adsorption capacity of the sorbent. Therefore, fewer amounts $\mathrm{CH}_{4}$ is stored during adsorption due to increase in temperature and more $\mathrm{CH}_{4}$ is retained during desorption due to decrease in temperature [12]. Temperature changes in the ANG system can be managed by incorporating heat exchanger in the storage vessel, changes in the tank geometry, modification of the sorbent material and changes in nature and direction of flow. Higher thermal conductivities and heat capacity is required for the sorbent. Material with high heat capacity is less susceptible to temperature changes during charging and discharging of natural gas [12].

A study was carried out to determine the thermal effect of the adsorption heat on the discharge performance of an adsorbed natural gas (ANG) storage system [14]. It was found out that central region of the adsorbent bed suffers from the severest temperature fluctuation in a short period of discharge state; introduction of the hot water greatly reduce temperature fluctuation of the adsorbent bed, shorten the discharge process by $60 \%$ compared to that without supplemental heat [14].

\subsection{Surface area and pore characteristics}

Adsorbent for natural gas application is desired to have large surface area, predominantly microporous with low mesoporosity. Large surface area allows more contact between gas adsorbate and the solid adsorbent which translate to more adsorption. Low mesoporosity is required as feeder pores to provide easy access for the gas molecules to/from the adsorbent micropores [5]. Micropores are pores that are less than $2 \mathrm{~nm}$, while mesopores are pores between 2 to $50 \mathrm{~nm}$ [15]. Surface area of activated carbon used for natural gas adsorption was in the range of few hundreds to $3000 \mathrm{~m}^{2} / \mathrm{g}$ [5].

Biloe' [16] used Dubinin-Astakhov equation to determine the influence of the microporous characteristics of activated carbon on the performances of both charge and discharge of an ANG system. It was found out that for the charge stage, the activated carbon must be conductive with an average micropore width of $1.5 \mathrm{~nm}$, and for the discharge, it should be permeable and sufficiently conductive with an average micropore width of $2.5 \mathrm{~nm}$.

\subsection{Packing Density}

Packing density is defined as the mass of settled material per unit volume of storage space. A carbon sorbent material with high surface area and low parking density would still have low adsorption capacity [13]. Therefore, in addition to high surface area, high packing density is required for sorbent materials to be used as an ANG material. More porosity development in a carbonaceous sorbent lowers its packing density [17]. An adsorbents may have high uptake on a mass basis, but with the low packing density much of the potential advantage is lost and the volumetric energy densities will still be low [13]

For economic viability of ANG, it's good to have high energy density besides the high micropore volume on volumetric basis. In order to achieve that, the sorbent must have high packing density. Packing density of slit pores $\mathrm{AC}$ is higher than due to the additional space given for freedom of molecules between to parallel sides of slit pores [18]. [7] reported packing density of about $0.7 \mathrm{~g} / \mathrm{ml}$ for activated carbon with BET surface area close to 2400 $\mathrm{m}^{2} / \mathrm{g}$.

\subsection{Other properties}

ACs for use as ANG materials are required to be hydrophobic, which prevents competition between water and adsorbate molecule. The adsorbent should be hard, not easily broken or powdered [5].

\section{Adsorption of Methane on AC}

Methane uptake is usually reported as adsorbed volume at standard pressure and temperature (cm3 (STP) per volume of sample $\left(\mathrm{cm} 3(\mathrm{STP}) \mathrm{cm}^{-3}\right)$, gravimetrically (cm3 (STP) $\mathrm{g}^{-1}$ ), specific amount reported in $\mathrm{mmol} \mathrm{g}^{-1}$, or as sample- specific weight percent (wt.\%) [19].

There are several studies conducted on use of activated carbon for methane adsorption. Activated carbon samples were prepared from Brazilian coconut shells modified by $\mathrm{H}_{3} \mathrm{PO}_{4}$ for methane adsorption [20]. The experiments were conducted at pressures between at $303 \mathrm{~K}$. highest methane storage capacity was found to be $95 \mathrm{v} / \mathrm{v}$ at $303 \mathrm{~K}$ and $35 \mathrm{bar}$ on the activated carbon samples. [21] prepared activated carbon (CAQF-30) from coconut shells by chemical activation with zinc chloride 
followed by physical activation. The performance of the prepared AC was compared with commercial AC (SRD21) for adsorption of methane. The prepared activated carbon showed approximately $0.14 \mathrm{~g} / \mathrm{g} \mathrm{CH}_{4}$ adsorption capacity, while the commercial sample showed $0.17 \mathrm{~g} / \mathrm{g}$ $\mathrm{CH}_{4}$ adsorption capacity.

Activated carbon from rice husk (AC-RH) was synthesized and its methane adsorption capacity was determined [22]. The experiment was conducted at constant temperature and pressure up to $2.5 \mathrm{Mpa}$. The AC-RH demonstrated $2350 \mathrm{~m}^{2} / \mathrm{g}$ BET surface area and 0.95 pore volumes. The sorbent had $9.3 \mathrm{mmol} / \mathrm{g}$ adsorption capacities at $303.15 \mathrm{~K}$ under $2.5 \mathrm{Mpa}$. Activated carbons (ACs) were prepared by carbonization, impregnation with $\mathrm{KOH}$ and activation of sugarcane molasses [23]. The AC that had high surface area of 2202 $\mathrm{m}^{2} / \mathrm{g}$ was evaluated for methane adsorption. Highest methane adsorption capacity of $197.23 \mathrm{mg} / \mathrm{g}$ (12.33 mmol g${ }^{-1}$ ) at 50 bars and $20{ }^{\circ} \mathrm{C}$ was recorded.

In another study, theoretical and experimental study was carried out to determine the amount of adsorption and desorption of methane on MERC commercial granular activated carbon [24]. The experiments were carried using volumetric method for pressure up to 500 psia at constant temperature of $25^{\circ} \mathrm{C}$. The adsorption and desorption capacity of the MERC activated carbon reached $0.127 \mathrm{~g} / \mathrm{g}$ and $0.091 \mathrm{~g} / \mathrm{g}$. It was found out that BET surface area, micropore volume, packing density, and pore size distribution have significant effect on the amount of methane adsorbed [24]. Delevar et al. (2010) investigated the capacity of granular activated carbon (GAC) for the storage of methane. The methane adsorption was determined at different pressures (0-50 bar) and temperatures $(285.15-328.15 \mathrm{~K})$. The $\mathrm{CH}_{4}$ adsorption capacity on the activated carbon samples was around $8 \mathrm{mmol} / \mathrm{g}$ at 298K, $40 \mathrm{bar}$. I t was also revealed increasing the pressure and decreasing the temperature increases the amount of adsorption.

\section{Adsorption of $\mathrm{CH}_{4}$ and $\mathrm{CO}_{2}$ Mixture}

Some sources of natural gas are associated with $\mathrm{CO}_{2}$, which is considered as an impurity. Presence of $\mathrm{CO}_{2}$ reduces the energy content and heating value of natural gas, in the presence of water it corrupt transportation and storage system $[25,26]$. There is also need to remove $\mathrm{CO}_{2}$ from the mixture in order to meet pipe line specification or to produce liquefied natural gas [26]. Adsorption on porous carbons is one of the techniques used to separate the $\mathrm{CH}_{4} / \mathrm{CO}_{2}$ gas mixture.

[27] used virgin palm shell activated carbon and PEI (polyethyleneimine) carbon molecular basket for methane and $\mathrm{CO}_{2}$ adsorption. Virgin palm shell $\mathrm{AC}$ shows 3.03 and $10.79\left(\mathrm{~cm}^{3} / \mathrm{gSTP}\right) \mathrm{CH}_{4}$ and $\mathrm{CO}_{2}$ adsorption capacity with 3.56 as $\mathrm{CO}_{2} / \mathrm{CH}_{4}$ ideal selectivity. PEI (polyethyleneimine) carbon molecular basket demonstrated 15.68 and $51.11\left(\mathrm{~cm}^{3} / \mathrm{gSTP}\right) \mathrm{CH}_{4}$ and $\mathrm{CO}_{2}$ adsorption capacity with 3.26 as $\mathrm{CO}_{2} / \mathrm{CH}_{4}$ ideal selectivity.

High-pressure adsorption of $\mathrm{CO}_{2}$ and $\mathrm{CH}_{4}$ in activated carbon was evaluated on Maxorb AC [26]. The researchers found out that $\mathrm{CO}_{2}$ is more adsorbed than $\mathrm{CH}_{4}$ in all the conditions tested. Maximum amount adsorbed (qmax) from Sips isotherm for $\mathrm{CO}_{2}$ and $\mathrm{CH}_{4}$ reached up to 31.97 and $15.02 \mathrm{~mol} / \mathrm{kg}$. There is deviation of up to $20 \%$ between results obtained from static and dynamic adsorption. In a similar study, Coconut activated carbons were prepared and used for $\mathrm{CO}_{2}$ and $\mathrm{CH}_{4}$ adsorption [28]. $\mathrm{CO}_{2}$ adsorption capacity of $2.55 \mathrm{mmol} / \mathrm{g}$ at $200 \mathrm{kPa}, \mathrm{CH}_{4}$ adsorption capacity of $1.93 \mathrm{mmol} / \mathrm{g}$ were recorded at $200 \mathrm{kPa}$.

In a similar study, methane adsorption was investigated on activated carbon obtained from coffee husks [29] at $298.15 \mathrm{~K}$ and $303.15 \mathrm{~K}$ and pressures up to $30.00 \mathrm{~atm}$. maximum volumetric methane uptake by the synthesised carbon monoliths was observed to be 130 $\mathrm{V} / \mathrm{V}$ at $298.15 \mathrm{~K}$ and $30.00 \mathrm{~atm}$. It was observed that there was increase in amount adsorbed due to increasing surface area, total pore volume and micropore volume.

[30] studied adsorption equilibrium of carbon dioxide, methane and nitrogen on microwave activated carbon (MAC). The capacities of pure gas $\mathrm{CO}_{2}, \mathrm{CH}_{4}$ and $\mathrm{N}_{2}$ were reported to be 2.13, 0.98 and $0.33 \mathrm{mmol} \mathrm{g}^{-1}$ at $298 \mathrm{~K}$ and the partial pressure of $100 \mathrm{kPa}$. [31] studied adsorption of methane and carbon dioxide on two microwave-activated carbon samples at different temperatures from 298 and $323 \mathrm{~K}$. The results showed that the activated carbon modified by potassium carbonate sample has the higher equilibrium selectivity for $\mathrm{CO}_{2}$ over $\mathrm{CH}_{4}$. The adsorption capacities of $\mathrm{CO}_{2}$ for unmodified and $\mathrm{K}_{2} \mathrm{CO}_{3}$ modified $\mathrm{AC}$ was $1.31 \mathrm{mmol} / \mathrm{g}$ and $1.63 \mathrm{mmol} / \mathrm{g}$ at $298 \mathrm{~K}$ and the pressure of $50 \mathrm{KPa}$, respectively. The ideal selectivity of $\mathrm{CO}_{2} / \mathrm{CH}_{4}$ is 2.66 and 7.42 for $\mathrm{MAC}$ and $\mathrm{MAC} / \mathrm{K}_{2} \mathrm{CO}_{3}$ respectively.

\section{Challenges and Improvements in ANG Technology}

The first issue is that, according to the thermodynamic laws, during the process of adsorption, the temperature of the ANG system is increased, there by limiting the amount of natural gas uptakes. During desorption the temperature of the system diminishes which causes retention of some of the gas to be delivered [32]. Therefore, management of thermal effects as a result of adsorption heat on both charge and discharge processes of the ANG are still a bottleneck for developing the vehicular ANG storage technology [14]. MoreGasTech, a French company develop an efficient thermo-managing control system for cooling during adsorption or heating the adsorbent during discharge [32]. Another sorbent challenge is presence of impurities in the methane gas [19]. They compete favourably with $\mathrm{CH}_{4}$ for pores and active sites. But issues related with impurity such as $\mathrm{H}_{2} \mathrm{O}$ could be avoided by having a hydrophobic surface.

The volumetric storage of ANG still needs to be improved in order to favourably compete with other NG storage method. Increasing the packing density will help in this regard. Compacting the sorbents increases the density which in turn increases the adsorption capacity per unit volume. Another is problem is the difficulty in 
direct packing of the adsorbent carbon into the storage vessel. Briquetting, or immobilizing, the carbon was considered as an alternative. But the binder blocks some of the pores there by reducing storage due to inaccessibility to the micropores [32]. Configuration, design and nature of the carbonaceous sorbent also enhance the storage capacity. New adsorbents such as monolithic carbons and compressed active carbon fibers used in non-cylindrical vessels have made possible to store the same capacity of gas as CNG tank [33].

\section{Conclusions}

Biomass materials which are precursors for producing activated carbon material are cheap and readily available. Utilization of biomass as an ANG material brings about cost effectiveness and improved profitability in ANG related industries, with concomitant waste minimization. Choice of proper synthesis and modification conditions leads to sorbent with the desired properties for natural gas adsorption. Emphasis should be on having a material that is microporous with little mesopore; a material with high packing density, high adsorption and desorption capacity, low isosteric heat of adsorptiont, good mechanical strength, tolerant to impurities and cheaper. Biomass based AC have great potential as adsorbents for natural gas storage. But still there need to improve the volumetric capacity to the driving range to levels closer to that of gasoline vehicles.

\section{Acknowledgement}

The authors acknowledge and appreciate the financial support provided by the Ministry of Higher Education Malaysia through University Teknologi Malaysia (UTM), Johor, Malaysia, to fully undertake this research under the Research University Grant (RUG) Q.J130000.2509.10H89 and Q.J130000.2509.06H79.

\section{References}

1. Esteves A.A.C.I., Lopes M.S.S., Nunes, P.M.C., Mota J.P.B. (2008). Adsorption of natural gas and biogas components on activated carbon. Separation and Purification Technology, 62, 281-296.

2. Adewole J.K., Ahmad A.L., Ismail S., Leo C.P. (2013). Current challenges in membrane separation of $\mathrm{CO} 2$ from natural gas: A review. International Journal of Greenhouse Gas Control, 17: 46-65

3. Liu B., Wang W., Wang N., Au C.T. (2014). Preparation of activated carbon with high surface area for high-capacity methane storage. Journal of Energy Chemistry, 23, 662-668.

4. Wang Y., Hashim M., Ercan C., Khawajah A., Othman R. (2011). High Pressure Methane Adsorption on Granular Activated Carbons. 21st Annual Saudi-Japan Symposium Catalysts in Petroleum Refining \& Petrochemicals Dhahran, Saudi Arabia, November, 2011.
5. Menon V.C., and Komarneni S. (1998). Porous Adsorbents for Vehicular Natural Gas Storage: A Review. Journal of Porous Materials 5, 43-58.

6. Delevar M. Ghoreyshi A.A., Jananshahi M., Khalili, S, and Nabian N. (2012). The effect of Chemical Treatment on Adsorption of Natural Gas by MultiWalled Carbon Nanotubes: Sorption Equilibria and Thermodynamic Studies. Chemical Industry \& Chemical Engineering Quarterly, 18 (2), 193-207.

7. Lozano V.M.P. \{n.d). Methane Storage in Activated Carbon Fibres. Universidat de Alicante.

8. Delavar M, Ghoreyshi A.A., Jahanshahi M., Irannejad M. (2010). Experimental Evaluation of Methane Adsorption on Granular Activated Carbon (GAC) and Determination of Model Isotherm. World Academy of Science, Engineering and Technology, 62, 47-50.

9. Ma, S. (2009). Gas adsorption applications of porous metal-organic frameworks. 2235 Pure Appl. Chem., Vol. 81, No. 12, pp. 2235-2251,

10. Casco M.E., Martínez-Escandell M., Gadea-Ramos E., Kaneko K., Silvestre-Albero J., and RodríguezReinoso F. (2015). High-Pressure Methane Storage in Porous Materials: Are Carbon Materials in the Pole Position. Chem. Mater. 27, 959-964.

11. Judd R.W., Gladding D.T.M., Hodriean R.C., Batcs D.R., Ingram J.P. M. Allen. (n.d). The Use of Adsorbed Natural Gas Technology for Large Scale Storage. BG Technology, Gas and Research Technology Centre, Loughbrough, U.K.

12. Mason, JA, Veenstra M. and Jeffrey R. (2014). Long Evaluating metal-organic frameworks for natural gas storage. Chem. Sci., 5, 32-51.

13. Mat T.H, Zakaria Z., Paouhe T.G. Development of Adsorbent Based Natural Gas Storage for Vehicle Application . Department of Chemical Engineering Faculty of Chemical And Natural Resources Engineering Universiti Teknologi Malaysia, VOT 72229. 1-1-100

14. Yang X.D., Zheng Q.R., Gu A.Z., Lu X.S. (2005). Experimental studies of the performance of adsorbed natural gas storage system during discharge. Applied Thermal Engineering 25: 591-601

15. IUPAC Manual of Symbols and Terminology, (1972). Appendix 2, 1, Colloid Surface Chem. Pure and AppI. Chem. 31, 587.

16. Biloe' S., Goetz V., Guillot A. (2002). Optimal design of an activated carbon for an adsorbed natural gas storage system. Carbon, 40, 1295-1308.

17. Rufford T.E., Zhu J., Hulicova-Jurcakova D. (2014). Green Carbon Materials: Advances and Applications. CRC Press, 6 Mar 2014 - Technology \& Engineering - pg.73.

18. Nalwa H S. (2001). Handbook of surfaces and interfaces of Materials. Volume 1, Surface and interface phenomena. Academic Press, San Francisco, USA. Pg. 337.

19. Bimbo N., Physick A.J., Noguera-Díaz A., Pugsley A., Holyfield L.T., Ting V.P., Mays T.J. (2015). High volumetric and energy densities of methane stored in nanoporous materials at ambient 
temperatures and moderate pressures. Chemical Engineering Journal 272, 38-47.

20. Rios R.B., Silva F.W.M., Torres A.E.B., Azevedo D.C.S., Cavalcante Jr C.L. (2009). Adsorption of methane in activated carbons obtained from coconut shells using $\mathrm{H}_{3} \mathrm{PO}_{4}$. chemical activation. Adsorption, 15: 271-277

21. Bastos-Neto M., Torres A.E.B., Azevedo D.C.S., and Cavalcante Jr C.L. (2005). Methane Adsorption Storage Using Microporous Carbons Obtained from Coconut Shell. Adsorption. 11: 911-915.

22. Balathanigaimani M.S., Kang H., Shim W., Kim C., Lee J. and Moo H. (2006). Preparation of powdered activated carbon from rice husk and its methane adsorption properties. Korean J. Chem. Eng, 23(4), 663-668.

23. Sren'scek-Nazzal, J.S., Kamin'ska, W., Michalkiewicz, B., Koren, Z.C. (2013). Production, Characterization and Methane Storage Potential of $\mathrm{KOH}-$ Activated Carbon from Sugarcane Molasses. Industrial Crops and Products, 47, 153- 159.

24. Salehi E., Ghotbi V.T.C., Lay E.N., Shojaei A. (2007). Theoretical and Experimental Study on the Adsorption and Desorption of Methane by Granular Activated Carbon at $25^{\circ} \mathrm{C}$. Journal of Natural Gas Chemistry, 16, 415-422

25. Xu X.L., Zhao X.X., Sun L.B., Liu X.Q. (2009). Adsorption separation of carbon dioxide, methane and nitrogen on monoethanol amine modified $b$ zeolite, J. Nat. Gas Chem. 18, 167-172

26. Grande C.A., Blom R., Moller A. and Mollmer J. (2013). High-pressure separation of $\mathrm{CH}_{4} / \mathrm{CO}_{2}$ Using Activated Carbon. Chemical Engineering Science, 89, $10-20$.

27. Aroua, M.K. WanDaud, W.A., Yin, C.A. and Adinata, D. (2008). Adsorption Capacities of Carbon Dioxide, Oxygen, Nitrogen and Methane on Carbon Molecular Basket Derived from Polyethyleneimine Impregnation on Microporous Palm Shell Activated Carbon. Separation and Purification Technology, 62 (3), 609-613.

28. Yang H, Gong M, ChenY. (2011). Preparation of activated carbons and their adsorption properties for greenhouse gases: $\mathrm{CH}_{4}$ and $\mathrm{CO}_{2}$. Journal of Natural Gas Chemistry 20, 460-464.

29. Giraldo, L., Moreno-Piraján, J.C. (2011). Novel Activated Carbon Monoliths for Methane Adsorption Obtained from Coffee Husks. Materials Sciences and Applications, 2, 331-339.

30. Yi H., Li F., Ning P., Tang X., Peng J., Li Y. and Deng H. (2013). Adsorption Separation of $\mathrm{CO}_{2}, \mathrm{CH}_{4}$, and $\mathrm{N}_{2}$ on Microwave Activated Carbon. Chemical Engineering Journal, 215-216, 635-642.

31. Ning P., Li F., Yi H., Tang X., Peng J., Li Y., He D., Deng H. (2012). Adsorption equilibrium of methane and carbon dioxide on microwave-activated carbon. Separation and Purification Technology, 98, 321326.

32. Ginzburg Y. (2006). ANG Storage As A Technological Solution For The "Chicken-And-Egg" Problem Of NGV Refuelling Infrastructure Development. 1-17.
33. Vasiliev, L.L., Kanonchik, L.E. Mishkinis D.A. and Rabetsky M.I. (2000). Adsorbed natural gas storage and transportation vessels. Int. J. Thermal Sci., 39, 1047-1055. 